\title{
Analysis of Patients Presenting with Dhat Syndrome and its Impact on Society
}

\author{
Dr. Amit Verma ${ }^{1}$, Dr. Shivam Priyadarshi ${ }^{2}$, Dr. Vinay Tomar ${ }^{3}$ \\ ${ }^{1}$ MCH Urology Resident, SMS Medical College, Jaipur-302004, Rajasthan, India \\ ${ }^{2} \mathrm{MCH}$ Urology, Professor Urology Department, SMS Medical College, Jaipur-302004, Rajasthan, India \\ ${ }^{3} \mathrm{MCH}$ Urology, Professor and Head of Urology Department, SMS Medical College, Jaipur-302004, Rajasthan, India
}

\begin{abstract}
Context: Misconceptions in relation to semen loss induces physical and psychological symptoms in a man which is termed as dhat syndrome. Aims: To find out the most predisposed group for dhat syndrome, its impact on their life, their surroundings and the whole society and what could be done to relieve them of their sufferings. Settings and design: Patients presenting with dhat syndrome were enquired about their demographic profile, clinical profile and its impact on their lives. Their counseling was done and the effect of counseling was observed. Method and material: In this study, 110 patients who presented in urology clinic of our institute during January 2015 to October 2015 with primary complaint of dhat were enquired about their demographic profile, clinical profile and their beliefs. To find the impact of their sufferings, they were asked few questions and the response was recorded as never, sometimes, regular. They were then counseled and sex education was imparted to them. Patients were then called for follow up after one week and again the same questions were asked. Statistical analysis: Descriptive analyses were analyzed in terms of mean and standard deviation for continuous variables. Frequency with percentage was used for nominal variables. Results: Dhat syndrome most commonly affected men who were in the age group 18-25 (60\%), were unemployed or students $(49.1 \%)$, were unmarried $(70 \%)$, lived in rural area (63.6\%), were either living alone (54.5\%) or in nuclear family (30\%), had low monthly income. It was also common in people with good educational status (50 \% graduate or above). Dhat syndrome had severe detrimental effects on every sphere of its sufferer's life. Counseling, correction of misbeliefs and reassurance only brought excellent results. Conclusion: Dhat syndrome is prevalent in a specific strata of population and have severe detrimental effects. Counseling, correction of misbeliefs and reassurance alone bring dramatic improvement in physical, mental and social health of the patients.
\end{abstract}

Keywords: Dhat, Misconceptions, Detrimental, Implications, Counseling

\section{Introduction}

Cultural beliefs prevalent in the society have a very severe impact on the mind and behavior of the person. Sexuality is a very important but under discussed domain in public as well as in our education system ${ }^{1,2}$. So there are many misbeliefs and misconceptions about sexuality prevalent in our society. Many cultures believe semen to be a very precious body fluid and its unnecessary loss to cause severe harm on the health of the person. Cultural myths in relation to semen loss can induce physical and psychological symptoms in a man which together as a syndrome termed as Dhat syndrome ${ }^{3}$. Đhat" is derived from the word -dhatu" which is a Sanskrit word which means -Metal" or Elixir"3,4

Dhat Syndrome is described in The Diagnostic and Statistical Manual (DSM) IV as a culture bound syndrome $(\mathrm{CBS})^{5}$. There is an ongoing debate on nosological status of $\mathrm{CBS}^{6}$. Dhat syndrome has been found to be prevalent in different geographical regions of the world ${ }^{7}$. It has been described in literature from China, Europe, America, and Russia at different points of time in history ${ }^{8}$.

The assumption that these cultures bound syndromes affect only specific cultures have resulted in limiting global interest in understanding these conditions and their management. However, these conditions are of serious concern as they have severe detrimental effects on the life of its sufferers. So we in our study tried to find out the most predisposed group for this syndrome, its impact on their life, their surroundings and the whole society and what could be done to relieve them of their sufferings.

\section{Subjects and Methods}

The study was approved by the ethics committee of our institution. The study included 110 patients who presented in the urology clinic of our institute during January 2015 to October 2015 with the primary complaint of involuntary discharge of semen. Informed consent was taken from all the patients before including them in the study. Patients were excluded from the study if they didn't appear for follow up as advised. The patients were provided comfortable atmosphere and were taken in to confidence that their information will not be disclosed. The patients were enquired about their demographic profile (like age, marital status, educational status, occupation, socio-economic status, family details). They were specifically asked about their personal life like their sexual history, drug abuse, alcohol and smoking. They were enquired about their primary complaint of dhat, timings of discharge, associated health problems or any sexual problem. They were asked about their beliefs regarding dhat, its reasons and the future cosequences. To find the impact of their suffering of dhat on their daily living, their health, their surroundings, their professional life and the society, they were asked few questions as listed below. 


\section{International Journal of Science and Research (IJSR) \\ ISSN (Online): 2319-7064}

Index Copernicus Value (2013): 6.14 | Impact Factor (2014): 5.611

During the past week, did they feel:

1. A vague feeling of fear?

2. Lack of energy?

3. Disturbed sleep?

4. Somatic symptoms like bodyache, fainting, dizziness etc.?

5. No interest in work?

6. No interest in surroundings?

7. Easily becomes irritated?

8. They can't enjoy anything anymore?

9. Easily become emotional?

10. That everything is meaningless?

11. Unnecessarily feeling afraid?

12. Afraid of going to social gatherings?

13. Feel of inferiority complex?

14. Feel life is not worthwhile?

15. Think - Ivish I was dead"?

The response was recorded as never, regular, sometimes.

Patients were counseled, taught about their condition in detail, were asked to raise their doubts and sexual education was imparted to them. Patients were then called for follow up after 1 week. Above questions were again asked.

Data was collected and Statistical analyses were performed using the Statistical Package for the Social Science Version (SPSS). Descriptive analyses were analyzed in terms of mean and standard deviation for continuous variables .Frequency with percent- age was used for nominal variables.

\section{Results}

\section{Assessment of demographic profile of Patients (as shown in Table 1)}

The study included 110 male patients presenting with Dhat syndrome. The mean age of study sample was 23.53 years with an age range of 15-68 years. The most affected age group was of 18-25 years which constituted about $60 \%$ of patients., about $25 \%$ were in the age range of 25-35 years, $10 \%$ were below 18 years while $5.5 \%$ patients were aged above 35 years.More than two-third $(70 \%)$ of the patients were unmarried, the rest were either married $(20 \%)$ or living separated $(10 \%)$. The condition had a high prevalence in educated population as well, and about $50 \%$ of patients were graduate or above. Majority of the patients were either unemployed or student $(49.1 \%)$. About half of patients had monthly family income between Indian Rupees 5000 to 10,000 and $24.5 \%$ people had monthly family income less than Indian Rupees 5000. The condition was prevalent in both urban and rural community with about $63 \%$ patients belonging to rural areas. Dhat syndrome was more common in people who were living alone $(54.5 \%)$ or in nuclear family (30\%) as compared to joint family and in people who had no previous history of having sex $(60 \%)$

\section{Assessment of clinical profile of the patients ( as shown in Table 2) \\ The mean duration of symptoms at the time of presentation was 22 months, and nearly $61 \%$ patients were passing dhat every week while one-fourth of patients were passing dhat at least once in a day. Most of the patients complained of}

passage of dhat while urination More than two-third of patients have not consulted anyone while about $20 \%$ have consulted quacks. When asked about associated sexual complaints, about $68 \%$ were worried about their habit of masturbation. About one third reported that their semen is thin and about $9 \%$ reported erectile dysfunction. Majority of patients reported generalized weakness, about $60 \%$ patients complained of constipation and about $9 \%$ reported burning micturition.

\section{Belief of patients}

$80 \%$ patients believed that they are losing semen in dhat while $20 \%$ had no idea. About $60 \%$ patients believed that they are passing dhat because of some defect they have created by doing masturbation (Graph 1). Majority of patients thought that if they continue to have dhat then they will get weak, while about $60 \%$ thought that they will be unable to have sex, about one fourth were worried that they will not be able to bear child (Graph 2).

\section{Impact on society}

It is clear from the response of patients to the questions asked (as shown in table 3 ), that dhat syndrome had severe impact on their daily living, their health, their surroundings, their professional life and the society. More than half of patients have regularly no interest in work and in their surroundings. About all the patents feel lack of energy and majority of patients also had disturbed sleep and complain of somatic symptoms like bodyache, fainting, dizziness. About half of patients regularly remain irritable. Significant number of patients thought that everything is meaningless, feel life is not worthwhile and even wish to be dead.

\section{Impact of counseling and reassurance}

Response of the patients at follow up after counseling to the same questions is shown in Table 4. By comparing the initial response of patients with the response after counseling and reassurance, it is clear that there was a dramatic positive response on the life of patients after counseling and reassurance only. Majority of patients though continued to have dhat, were able to take interest in their work, their surroundings and in their own life. Majority of patients were able to have a healthy physical, mental and social wellbeing.

\section{Discussion}

Dhat syndrome, although described as culture bound syndrome, has been found to be prevalent in different geographical regions of the world and has been found to be emerging in other countries as well. A significant number of patients with dhat syndrome come to urologist consultation but there have been very limited reports that describe or analyse this syndrome in urological literature ${ }^{9}$. In the case of dhat syndrome, the nature of underlying belief, i.e., semen is the most vital fluid and has to be conserved at any $\operatorname{cost}^{\text {' }}$ is such that there is intense distress in the wake of continued loss of dhat ${ }^{10}$. Sumathipala et al. ${ }^{11}$ and Balhara et al. ${ }^{6}$ have reported that dhat syndrome was not confined to Oriental countries infact it was prevalent in Europe, USA and Australia in the nineteenth century.

In our study we found that dhat syndrome is mainly prevalent in particular strata of population: young male,

\section{Volume 4 Issue 12, December 2015}




\section{International Journal of Science and Research (IJSR) \\ ISSN (Online): 2319-7064}

Index Copernicus Value (2013): 6.14 | Impact Factor (2014): 5.611

living alone or in nuclear family, with low income, although more common in rural community but is also prevalent in urban areas, common in illiterate as well as well educated men. Few previous studies conducted by Chaddha et al. ${ }^{12}$, Grover $\mathrm{S}$ et al. ${ }^{13}$ and Gautam $\mathrm{M}$ et al. ${ }^{14}$ reported that patients complaining of Dhat Syndrome are typically more likely to be young people, who are recently married or single; of average or low socio-economic status, coming from a rural area and belonging to a family with conservative attitudes towards sex while a study conducted by Verma $\mathrm{R}$ et al. ${ }^{15}$ reported more prevalence from urban area

In our study, the mean duration of symptoms at the time of presentation was 22 months, and nearly two-third of patients were passing dhat every week while one-fourth of patients were passing Dhat at least once in a day. In a recent study conducted in Spain by Menendez .V et al. ${ }^{9}, 25 \%$ of patients complained of daily sperm loss while in $37.5 \%$ it was weekly and patients complained of the syndrome lasting from 3 months up to 10 years. In a study conducted by De Silva $\mathrm{P}$ et al. ${ }^{16}$ complaint of duration of the semen loss lasts up to 20 years.

As reported by Grover S et al. ${ }^{17}$ and Rajkumar $\mathrm{R}$ et al. ${ }^{18}$,our study also showed that patient complaining of passage of dhat also complains of various somatic symptoms most common being generalized weakness (86.4\%) and constipation $(59.1 \%)$ and also some irrelevant sex related problems like fear of thin semen or small penis.

Most of the patients believed that they are losing semen in dhat and more than half of patients consider this to be a consequence of their habit of masturbation. Infact their self guilt of masturbation due to the misconceptions prevalent in the society lead to these false attributes ${ }^{19}$

They are so much threatened by the misbeliefs in the society that they believe that they will get very weak and will not be able to do sex or bear child. Due to these fears their physical and mental health; and personal and social life get so much disturbed as clearly shown by our study that they lose all their interest in their work, their surroundings and have a feel of fear and tiredness.

Various treatment strategies have been recommended with varying results in the literature. Avasthi A et al. ${ }^{20}$ had advised a standardized treatment protocol that mainly includes sex education, bio-feedback and relaxation exercises. Bhatia et al. ${ }^{21}$ obtained the best result using tranquillizers, Menendez $\mathrm{V}$ et al. ${ }^{9}$ have reported best results using multivitamin, Wigg $\mathrm{NN}$ et al. ${ }^{22}$ recommended proper counseling along with placebo, anti-anxiety and antidepressant drugs as required while Avasthi A et al. ${ }^{23}$ recommended sex education and relaxation exercises.

Our study clearly showed excellent results by the approach of emphatic listening, correction of misconceptions, sex education and reassurance. There is dramatic improvement in the lifestyle of the patients.

\section{Conclusion}

The results of our study clearly showed that dhat syndrome have a severe impact on the physical, mental and social health of the patient. This condition is more common in a specific strata of population mainly young people living alone or nuclear families having low income, more common in rural areas but also prevalent in urban areas, both illiterate as well as well educated men. Counseling, correction of misbeliefs, sex education and reassurance alone brings dramatic improvement in the physical, mental and social health of the patient. So sex education should also be incorporated in our education system.and counseling camps should be organized focusing to predisposed population.

Table 1 (Original)

Demographic profile of the patients

\begin{tabular}{|c|c|c|c|c|c|}
\hline Age & $<18(10 \%)$ & $18-25(60 \%)$ & $25-35(24.5 \%)$ & $>35(5.5 \%)$ & \\
\hline Educational status & Illiterate $(22.7 \%)$ & Up to 10 th $(27.3 \%)$ & Up to graduate $(45.5 \%)$ & $\begin{array}{c}\text { Above graduate } \\
(4.5 \%)\end{array}$ & \\
\hline Occupation & $\begin{array}{c}\text { Unemployed /Student } \\
(49.1 \%)\end{array}$ & $\begin{array}{c}\text { Unskilled worker } \\
(20 \%)\end{array}$ & Skilled worker (17.2\%) & $\begin{array}{c}\text { Clerical /farmer } \\
(8.2 \%)\end{array}$ & Professional $(5.5 \%)$ \\
\hline Monthly family income & $<5000(24.5 \%)$ & $5000-10000(50 \%)$ & $10000-20000(20 \%)$ & $>20000(5.5 \%)$ & \\
\hline Marital status & Un married $(70 \%)$ & Married (20\%) & Separated $(10 \%)$ & & \\
\hline Previously ever had sex & No $(60 \%)$ & Yes $(40 \%)$ & & & \\
\hline Type of family & Nuclear $(30 \%)$ & Joint $(15.5 \%)$ & Alone $(54.5 \%)$ & & \\
\hline Residence & Rural (63.6\%) & Urban $(36.4 \%)$ & & & \\
\hline Smoker & Yes $(54.5 \%)$ & No $(45.5 \%)$ & & & \\
\hline Alcoholic & Regular $(20 \%)$ & Occasional (45.5\%) & Never $(34.5 \%)$ & & \\
\hline Drug abuse & Yes $(20 \%)$ & No $(80 \%)$ & & & \\
\hline
\end{tabular}




\section{International Journal of Science and Research (IJSR)}

ISSN (Online): 2319-7064

Index Copernicus Value (2013): 6.14 | Impact Factor (2014): 5.611

Table 2 (Original)

Clinical profile of the patients

\begin{tabular}{|c|c|c|}
\hline & $\mathbf{n}$ & \%age \\
\hline \multicolumn{3}{|l|}{ Duration of suffering } \\
\hline$<6$ months & 12 & 10.9 \\
\hline 6months-1year & 23 & 20.9 \\
\hline$>1$ year & 75 & 68.2 \\
\hline \multicolumn{3}{|l|}{ Frequency of passage of dhat } \\
\hline Everyday & 29 & 26.4 \\
\hline Every week & 67 & 60.9 \\
\hline Once a while & 14 & 12.7 \\
\hline \multicolumn{3}{|l|}{ When they have passage of dhat ${ }^{*}$} \\
\hline While passing urine & 75 & 68.2 \\
\hline While straining for passing stools & 10 & 9.1 \\
\hline During sleep & 50 & 45.4 \\
\hline While sexual excitement & 40 & 36.4 \\
\hline Anytime & 25 & 22.7 \\
\hline \multicolumn{3}{|l|}{ What they have done till now for this } \\
\hline Nothing & 74 & 67.3 \\
\hline Consulted quacks & 24 & 21.8 \\
\hline Consulted doctors & 12 & 10.9 \\
\hline \multicolumn{3}{|c|}{ Any associated sexual complaint reported by patients* } \\
\hline Erectile dysfunction & 10 & 9.1 \\
\hline Premature ejaculation & 5 & 4.5 \\
\hline Masturbation & 75 & 68.2 \\
\hline Thin semen & 35 & 31.8 \\
\hline Small penis & 5 & 4.5 \\
\hline No other sex related symptoms & 10 & 9.1 \\
\hline \multicolumn{3}{|c|}{ Any associated health problem reported by patient* } \\
\hline Constipation & 65 & 59.1 \\
\hline Generalized weakness & 95 & 86.4 \\
\hline Insomnia & 40 & 36.4 \\
\hline Body ache & 45 & 40.9 \\
\hline Anxiety & 60 & 54.5 \\
\hline Burning micturition & 10 & 9.1 \\
\hline No refer to any other associated health problem & 2 & 1.8 \\
\hline
\end{tabular}

*A patient can have more than one response

\section{Table 3 (Original)}

Response of the patients to questions asked to find the impact of their suffering of dhat on their daily living, their health, their family and surroundings, their professional life and the society:

\begin{tabular}{|l|l|l|l|}
\hline During the past week, did they feel: & Never $\mathbf{n}(\boldsymbol{)})$ & Sometimes n(\%) & Regular $\mathbf{n}(\boldsymbol{\%})$ \\
\hline A vague feeling of fear? & $13(11.8)$ & $64(58.2)$ & $33(30)$ \\
\hline Lack of energy? & $0(0)$ & $35(31.8)$ & $75(68.2)$ \\
\hline Disturbed sleep? & $18(16.4)$ & $54(49.1)$ & $38(34.5)$ \\
\hline Somatic symptoms like bodyache, fainting, dizziness etc. & $18(16.4)$ & $43(39.1)$ & $49(44.5)$ \\
\hline No interest in work? & $18(16.4)$ & $33(30)$ & $59(53.6)$ \\
\hline No interest in surroundings & $16(14.6)$ & $37(33.6)$ & $57(51.8)$ \\
\hline Easily becomes irritated & $21(19.1)$ & $35(31.8)$ & $54(49.1)$ \\
\hline They can't enjoy anything anymore & $23(20.9)$ & $44(40)$ & $43(39.1)$ \\
\hline Easily become emotional & $18(16.4)$ & $38(34.5)$ & $54(49.1)$ \\
\hline That everything is meaningless & $23(20.9)$ & $52(47.3)$ & $35(31.8)$ \\
\hline Unnecessarily feeling afraid & $28(25.5)$ & $34(30.9)$ & $48(43.6)$ \\
\hline Afraid of going to social gatherings & $38(34.5)$ & $44(40)$ & $28(25.5)$ \\
\hline Feel of inferiority complex & $23(20.9)$ & $28(25.5)$ & $59(53.6)$ \\
\hline Feel life is not worthwhile & $33(30)$ & $46(41.8)$ & $31(28.2)$ \\
\hline Think I wish I was dead" & $38(34.5)$ & $49(44.6)$ & $23(20.9)$ \\
\hline
\end{tabular}




\section{International Journal of Science and Research (IJSR) \\ ISSN (Online): 2319-7064}

Index Copernicus Value (2013): 6.14 | Impact Factor (2014): 5.611

\section{Table 4 (Original)}

At follow up, after counseling and sex education, correction of misbeliefs and reassurance, response of the patients to similar questions:

\begin{tabular}{|c|c|c|c|}
\hline During the past week, did they feel: & $\operatorname{Never} n(\%)$ & Sometimes $n(\%)$ & Regular $n(\%)$ \\
\hline A vague feeling of fear? & $84(76.3)$ & $19(17.3)$ & $7(6.4)$ \\
\hline Lack of energy? & $78(70.9)$ & $24(21.8)$ & $8(7.3)$ \\
\hline Disturbed sleep? & $76(69.1)$ & $27(24.5)$ & $7(6.4)$ \\
\hline Somatic symptoms like bodyache, fainting, dizziness etc. & $80(72.7)$ & $22(20)$ & $8(7.3)$ \\
\hline No interest in work? & $84(76.3)$ & $19(17.3)$ & $7(6.4)$ \\
\hline No interest in surroundings & $82(74.5)$ & $20(18.2)$ & $8(7.3)$ \\
\hline Easily becomes irritated & $74(67.3)$ & $26(23.6)$ & $10(9.1)$ \\
\hline They can't enjoy anything anymore & $76(69.1)$ & $26(23.6)$ & $8(7.3)$ \\
\hline Easily become emotional & $79(71.8)$ & $18(16.4)$ & $13(11.8)$ \\
\hline That everything is meaningless & $82(74.5)$ & $17(15.5)$ & $11(10)$ \\
\hline Unnecessarily feeling afraid & $74(67.3)$ & $23(20.9)$ & $13(11.8)$ \\
\hline Afraid of going to social gatherings & $79(71.8)$ & $21(19.1)$ & $10(9.1)$ \\
\hline Feel of inferiority complex & $76(69.1)$ & $23(20.9)$ & $11(10)$ \\
\hline Feel life is not worthwhile & $89(80.9)$ & $15(13.6)$ & $6(5.5)$ \\
\hline Think _I wish I was dead" & $92(83.6)$ & $14(12.7)$ & $4(3.7)$ \\
\hline
\end{tabular}

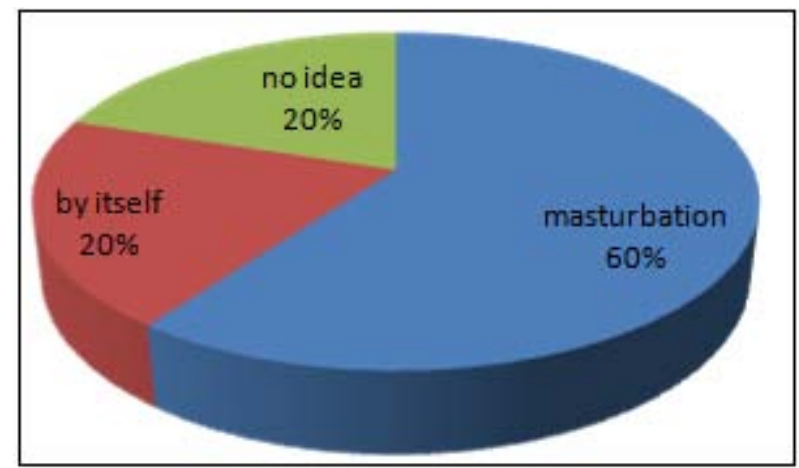

Graph 1 (Original)

Pie chart of belief of the patients about what they think is responsible for their sufferings

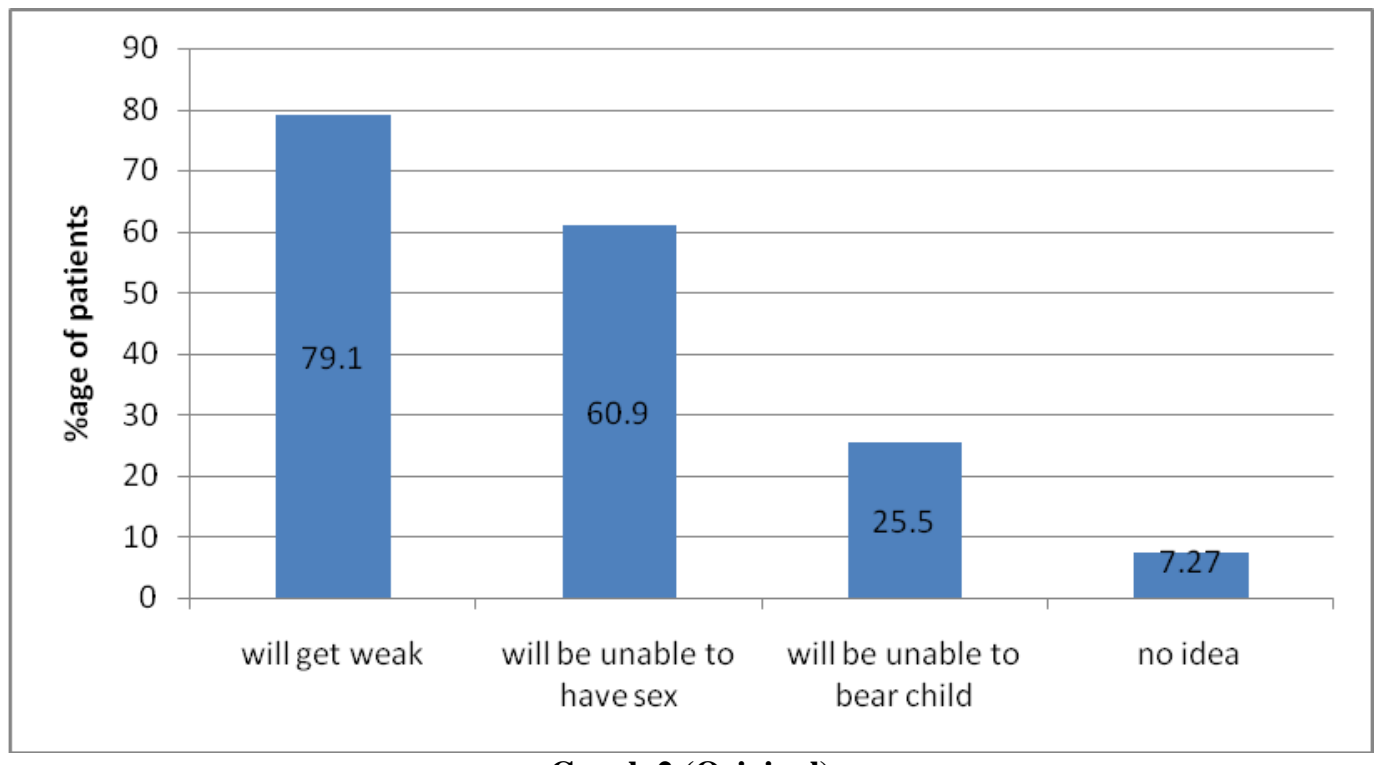

Graph 2 (Original)

Bar diagram about the belief of the patients about what will be the consequences if they continue to have dhat syndrome

\section{Conflict of Interest}

None

\section{References}

[1] Prakash O, Rao TS. Sexuality research in India: An update. Indian J Psychiatry 2010;52:S260-3.

[2] Avasthi A, Grover S, Kaur R, Prakash O, Kulhara P. Impact of nonorganic erectile dysfunction on spouses: A study from India. J Sex Med 2010;7:3666-74.

\section{Volume 4 Issue 12, December 2015}




\section{International Journal of Science and Research (IJSR) \\ ISSN (Online): 2319-7064}

Index Copernicus Value (2013): 6.14 | Impact Factor (2014): 5.611

[3] Prakash O. Lessons for postgraduate trainees about Dhat syndrome. Indian J Psychiatry 2007;49:208-10.

[4] Money J, Prakasam KS, Joshi VN. Semen-conservation doctrine from ancient ayurvedic to modern sexology theory. Am J Psychother 1991;45:9-13.

[5] Wig NN. Problems of mental health in India. J Clin Social Psychiatry(India) 1960;17:48-53.

[6] Balhara Y. Culture-bound syndrome: Has it found its right niche? Indian J Psychol Med 2011;33:210-5.

[7] Sumathipala A, Siribaddana SH, Bhugra D. Culture-bound syndromes: The story of dhat syndrome. Br J Psychiatry 2004;184:200-9.

[8] Mumford DB. The Dhat syndrome': A culturally determined symptom of depression? Acta Psychiatr Scand 1996;94:163-7.

[9] Menendez .V, Fernández-Suárez A, Placer J, GarcíaLinares M, Tarragon S, Liso E. Dhat syndrome, an emergent condition within urology in Spain.World J Urol 2013;31:941-5

[10] Prakash S, Sharan P, Sood M. A study on phenomenology of dhat syndrome in men, New Delhi (Thesis submitted to the faculty of All India Institute of Medical Sciences); 2012.

[11] Sumathipala A, Siribaddana SH, Bhugra D.Culturebound syndromes: the story of dhat syndrome. $\mathrm{Br} \mathrm{J}$ Psychiatry 2004;184:200-9

[12] Chadha C, Ahuja N. Dhat syndrome. A sex neurosis of the Indian subcontinent. Br J Psychiatry 1990;156:5779

[13] Grover S , Avasthi A, Aneja J, Shankar G, Mohan M R, Nehra $\mathrm{R}$ et al. Comprehensive Questionnaire for Assessment of Dhat Syndrome: Development and Use in Patient Population. J Sex Med 2014;11:2485-95

[14] Gautam M, Singh R, Weiss H, Brugha R, Patel V, Desai $\mathrm{NG}$ et al. Socio-cultural, psychosexual and biomedical factors associated with genital symptoms experienced by men in rural India. Tropical Medicine and International Health 2008; 13:384-95

[15] Verma R, Mina S, Hassan S, Balhara YPS. A Descriptive Analysis of Patients Presenting to Psychosexual Clinic at a Tertiary Care Center. Indian Journal of Psychological Medicine 2013;35:241-7.

[16] De Silva P, Dissanayake SA. The loss of semen syndrome in Sri Lanka: a clinical study. Sex Marital Ther 1989; 4:195-204

[17] Grover S, Avasthi A, Gupta S, Dan A, Neoqi R, Behere $\mathrm{PB}$ et al. Phenomenology and beliefs of patients with Dhat syndrome: A nationwide multicentric study. International Journal of Social Psychiatry 2015, http://dx.doi.org/10.1177/0020764015591857

[18] Rajkumar R. Dhat syndrome: Evidence for a depressive spectrum subtype. Asian Journal of Psychiatry 2014;9: $57-60$

[19] El Hamad I, Scarcella C, Pezzoli MC, Bergamaschi V, Castelli F. Forty meals for a drop of blood. J Travel Med 2009;16:64-5

[20] Avasthi A, Gupta N. Standardised management of single males with sexual disorders. Marital and Psychosexual Clinic Department of Psychiatry, PGIMER, Chandigarh.2002

[21]Bhatia MS, Malik SC. Dhat syndrome-a useful diagnostic entity in Indian culture. $\mathrm{Br} \mathrm{J}$ Psychiatry 1991;159:691-5.
[22] Wig NN. Dhat Syndrome. In: Brahmbhatt R, editor. Therapy of common sexual problems-A hand book. Mumbai: Family Planning Association of India;1998. .

[23] Avasthi A, Jhirwal OP. The concept and epidemiology of Dhat syndrome. J Pak Psychiatr Soc 2005;2:6-8 